\title{
Design a multi-motion bed to help the Elderly people and sick
}

\author{
Nisreen Kareem Ali ${ }^{1}$, Mustafa Yaseen Abdulateef ${ }^{2}$, Mohammed Hasan Ali $^{3}$ \\ ${ }^{1,2}$ Electrical Engineering Department, Heteen Secondary School, Diyala, Iraq \\ ${ }^{3}$ Collage of Engineering, University of Diyala, Diyala, Iraq
}

\begin{tabular}{l}
\hline \hline Article Info \\
\hline Article history: \\
Received Apr 7, 2021 \\
Revised Sep 12, 2021 \\
Accepted Sep 17, 2021 \\
\hline
\end{tabular}

Keywords:

Arduino

DC motor

Oximeter

Smart bed

\begin{abstract}
Most mishaps happening at clinical foundations treating older patients with portability hindrance are bedsores and slip-and-fall accidents. One reason for this high pace of mishaps is the absence of nursing faculty. So as to help parental figures in nursing old patients who are unable to move freely, we offer an arrangement and implementation of a wise bed in this work. This is the bed. Under the sheet material spread, a couple of weight sensors are passed to consider the two social orders' regular actual characteristics as well as the specific body portions where bedsores commonly arise. The body zone is divided into three vertical territories and three level zones to cope with the weight ulcer territory and prevent falls. Each microcontroller unit is in charge of monitoring pressure-differentiating data in one of the bodily regions separated on a level plane. In this review, a consistent weight distinguishing figure is offered that is useful for predicting the anticipated outcomes of bedsores and falling setbacks by taking into account both the strength and the length of weight of unambiguous body parts. Our preliminary findings reveal that a model magnificent bed serves a pair of human models of varied heights and burdens admirably.
\end{abstract}

This is an open access article under the CC BY-SA license.

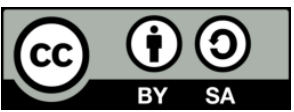

\section{Corresponding Author:}

Nisreen Kareem Ali

Electrical Engineering Department, Heteen Secondary School

Diyala, Baquba, 32001, Iraq

Email: mscnisreenkareem@gmail.com

\section{INTRODUCTION}

As of late, Iraq government has confronted the test of the quickly maturing society. Consequently, the issue of the old patients' consideration gets significant. Also, an expanding number of specific clinical foundations Habitats (called sanatoria) have been set up for old and senior consideration. Notwithstanding, the quick development of the business identified with the old consideration and the foundation of pertinent organizations experiences numerous issues, including, among others, the absence of proper organization [1].

On the off chance that an older individual is similarly situated for a really long time, the breakdown between both the skin and the surfaces of the body might cause the blood flow to halt. Whether in bed or in a wheelchair, making the weight territory get less oxygen and hence making the cells kick the bucket here [2]. This is the way bedsores will create. Weight ulcers in old people can cause noteworthy grimness and mortality and are a significant financial weight to the medical services framework [3].

Late reviews have assessed a tremendous consumption on direct clinical expense for homegrown mishaps (in the United States, in subjects $>65$ years old, over than approximately usd19 billion for nonfatal falls; Approximately usd1.9 billion for crisis management and hospitalization in the United Kingdom; and approximately usd 66.1 million for public medical care for old falls according to an Australian investigation) [4], [5]. The events of bedsores and dropping mishaps among older patients are normal problems, representing over $80 \%$ of such clinical organizations [6]. Operational guidelines for clinical foundations have 
been issued by the Ministry of Health and Welfare of Iraq and the last measure of the risk of falls and weight ulcers has been taken using these guidelines [7], [8].

Internet of things (IoT) upheaval is overhauling current medical services with promising innovative, monetary, and social possibilities. Empowered by the worldwide availability of the IoT, all the medical services data (coordinations, analysis, treatment, recuperation, prescription, the executives, fund, and even day by day movement) can be gathered, overseen, and used all the more proficiently. Among the array of uses empowered by the IoT, brilliant and associated medical care is an especially significant one. Sensors, either worn on the body or mounted in our living spaces, allow for the social exchange of rich physical and mental health data [9]. In this paper, we modify an IoT-based smart bed system focused at assisting caregivers in cultivating elderly patients with limited flexibility [10].

This is how the rest of the document is put together [11]. The second segment summarizes related jobs. In section 3, we go over the general engineering and specific tasks of a keen bed structure. Section 4 introduces the trial results that were used to approve the suggested approach. Finally, the ends of the segment are attracted to [12], [13].

\section{SMART BED SYSTEM}

The planned smart bed structure's principal purpose is to aid parents who are unable to move around freely while caring for elderly people. A few weight sensors put beneath the sleeping pad spread with a sharp bed measure pressure force caused by the patient's weight. The concentrations or locations of the patient's body's weight strength may be revealed by a dazzling bed [14].

One of the most critical elements of the shrewd bed system is that the patient's basic purposes can be found without much of a stretch. A savvy bed structure can perceive the recognized focuses where bedsores often occur, i.e., In light of the typical body size by age, occiput, scapula, short fibers projection, elbow, iliac peak, lumbar, pubic bone, Achilles ligam. As shown in Figure 1 [15].

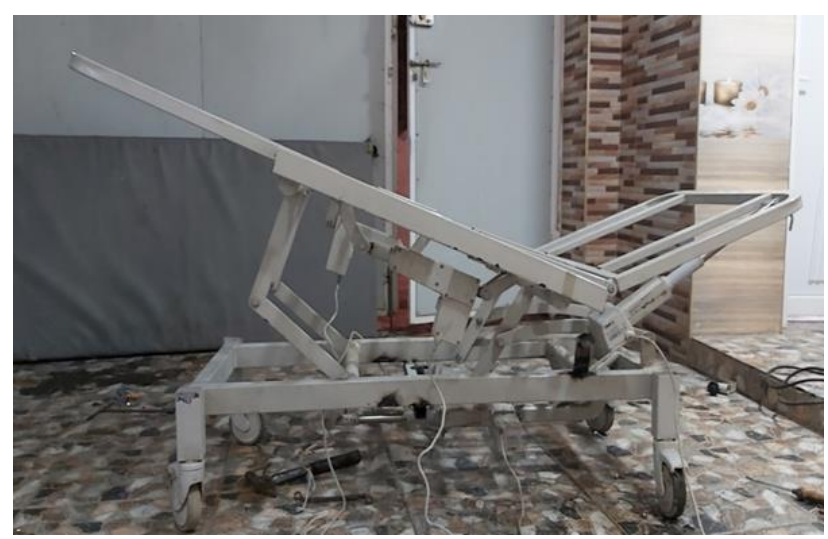

Figure 1. Model of bed

\section{DESIGNATION OF TWO SENSOR FORMS}

The weight sensor should be arranged depending on the particular age group's average body size. If a specific body part's weight is to be measured, the weights of the physical feature for each age collection should be expressed in the sensor position calculation. In terms of both the average body size by age, as determined by the KATS, and the position of the subsequent bedsor case, we have transmitted sensors. Doing so would make it conceivable to classify weight for various body measurements and body positions [16].

The goal of our sensor-sending technique is to determine the weight of all possible body positions using the minimum number of sensors. There are regions that need accurate weight estimate, depending on the body component, and those that don't Rather than estimating the weight of a specific area of the head and lower body, for example, it is just necessary to determine whether the weight is created [17].

The chest area, on the other hand, must carefully define the weight around a specific location where the weight ulcer happens most of the time. We'll use two different sensors in this case: the FSR-408 and also the FSR-406. Such sensors are chosen for their cost effectiveness and ease of use [18]. This power affectability is improved for usage technological control with a human touch gadget, such as car hardware, clinical frameworks, and current and technical technology applications, according to the sheet of specifics 
[19]. The FSR-408 sensor (strip-type) is used to determine whether a weight has been produced. Alternatively, the FSR-406 sensor (square type) is utilized to unambiguously compute the weight of a specified spot. The components of FSR-408 \& FSR-406 are $610 \mathrm{~mm} \times 5 \mathrm{~mm}$ and $38 \mathrm{~mm} \times 38 \mathrm{~mm}$. The weight area for the two sensors mentioned above is $0.1 \mathrm{~N}$. (Newton). Both the FSR-406 \& FSR-408 are two-wire devices with a power-dependent objection. With increasing power, the estimated resistor yield voltage rises. With fairly smaller numbers, the FSR-408 weight sensor can recognize the weight of a vast region. It simply knows the weight's quality; it has no notion what the pressure situation is like [20], [21].

\section{HARDWARE DESCRIBSTION}

The smart bed is made up of the following sections:

\subsection{Arduino nano}

A microcontroller-based open-source electrical circuit operated by a personal computer (PC) is used to encourage the usage of on an electronic progress board, intelligent hardware in transdisciplinary endeavors that speaks to the company's electronic identity. Arduino is mostly utilized in the development of smart ebusinesses or projects aimed at creating unique natural sensors. Temperature, twist, weight, and light are just a few examples. Arduino may be used with a variety of projects on a computer and uses an open-source programming language. The language code is similar to $\mathrm{C}++$ and is one of the most basic programming dialects for creating microcontroller programs as shown in Figure 2 [22].

\subsection{DC motor}

A DC motor, number 2, was used for the purpose of controlling movements and adjusting the patient's position to the comfortable position [23], as shown in the pictures in Figure 3.

\subsection{Pulse oximeter (SPO2) finger heart rate}

The oxy meter is specialized in the manufacture of medical devices, and it is characterized by accurate and stable reading, high efficiency and very accurate reading [24]. The results appear on the screen in four directions, that is, it can be displayed horizontally or vertically with a place designated for precise settings, as the device is equipped with an organic light-emitting diode (OLED) screen that consumes less energy and is two-color with display of heart rate and oxygen saturation percentage digitally and in the form of a continuous wave over time. Small size with a special lanyard to tie and carry easily. The device turns itself off if not used after only 8 seconds, and it works on two regular batteries [25]. The image of this sensor is shown in Figure 4.

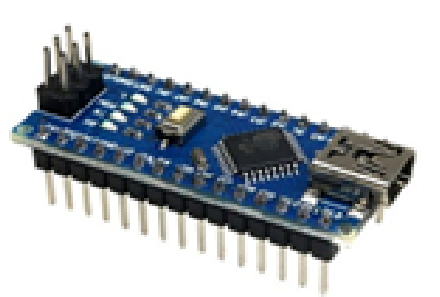

Figure 2. Arduino board

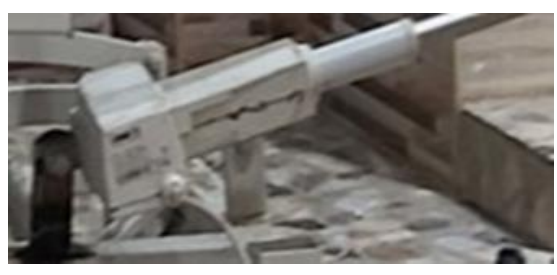

Figure 3. DC motor

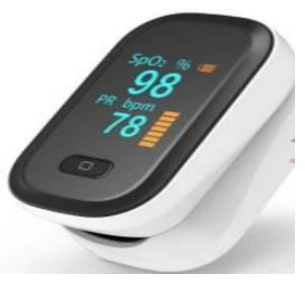

Figure 4. Pulse oximeter SPO2

\section{RESULTS}

The mechanical work of the clinical electrical dam was cultivated by setting various places that encourage the patient's development, and the bed space was browsed length and width as per worldwide norms. Where we gave two essential developments in the bed, the main development is the development of resting or resting, where the bed is completely reached out at a point of 180 degrees. With respect to the second essential development, it lies in the chance of transforming the bed into a hot seat where the electric bed is planned as three sections, the upper aspect of the bed that is found It has the heaviness of the back, shoulders, head, center part, and lower part that bear the legs weight. As the bed is planned utilizing 6 jacks, it can lift a greatest load of (patient's weight) by $250 \mathrm{~kg}$ shown in Figure 5. 


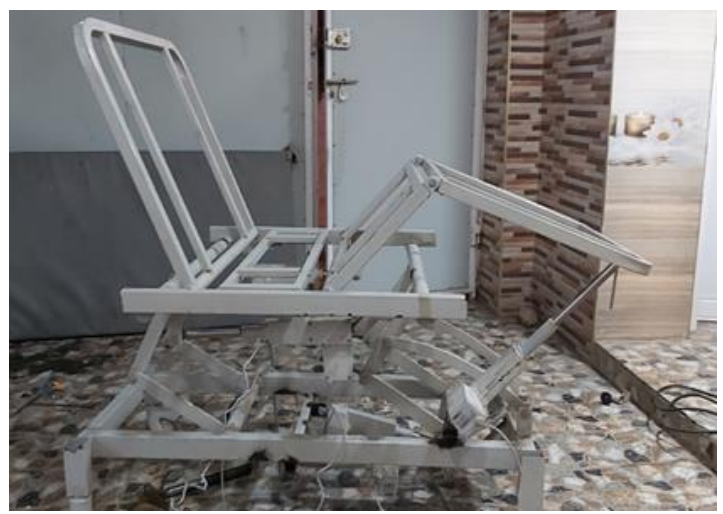

Figure 5. The iron frame of the bed

\section{CONCLUSION}

Our savvy bed model framework can detect pressure happening on the whole body of a patient with versatility hindrance at an ordinary span through a productive organization of sensors, while utilizing fewer sensors. Also, the proposed framework can identify the situation with the most elevated chance of bedsore assault by finding the biggest aggregated weight. In addition, research is always encouraging new or updated technological integrations within this family of products. These modifications are projected to spread into more automation and design adjustments in the future, with the smart bed serving as the hub of the smart patient-care environment. For future work, we can develop the bed by adding an application that is controlled by the mobile phone

\section{REFERENCES}

[1] M. Gayathri, P. Selvakumari, and R. Brindha, "Fingerprint and GSM based Security System," International Journal of Engineering Sciences Research Technology, vol. 3, no. 4, pp. 4024-4029, April 2014, doi: 10.29121/ijesrt.v10.i3.2021.14

[2] T. T. Yoshikawa, N. J. Livesley, and A. W. Chow, "Infected pressure ulcers in elderly individuals," Clinical Infectious Diseases, vol. 35, no. 11, pp. 1390-1396, 2002, doi: 10.1086/344059.

[3] M. Sartini et al., "The epidemiology of domestic injurious falls in a community dwelling elderly population: An outgrowing economic burden," European Journal of Public Health, vol. 20, no. 5, pp. 604-606, 2010, doi: 10.1093/eurpub/ckp165.

[4] G. D. Velhal, "Domestic accidents among the elderly," Annals of Tropical Medicine and Public Health, vol. 5, no. 2, pp. 61-62, 2012, doi: 10.4103/1755-6783.95950.

[5] Y.-O. Hwang, "Geriatric care facilities: recent trends in risk management," Journal of the Korean Gerontological Society, vol. 26, no. 3, pp. 505-520, 2006.

[6] S. M. R. Islam, D. Kwak, H. Kabir, M. Hossain, and K. Kwak, "The internet of things for health care: a comprehensive survey," in IEEE Access, vol. 3, pp. 678-708, 2015, doi: 10.1109/ACCESS.2015.2437951.

[7] M. C. Domingo, "An overview of the internet of things for people with disabilities," Journal of Network and Computer Applications, vol. 35, no. 2, pp. 584-596, 2012, doi: 10.1016/j.jnca.2011.10.015.

[8] S. Amendola, R. Lodato, S. Manzari, C. Occhiuzzi, and G. Marrocco, "RFID technology for IoT-based personal healthcare in smart spaces," in IEEE Internet of Things Journal, vol. 1, no. 2, pp. 144-152, April 2014, doi: 10.1109/JIOT.2014.2313981.

[9] A. Hamas, A. Muneer, and S. M. Fati, "Smart security door system using SMS based energy harvest," International Journal of Electrical and Computer Engineering, vol. 11, no. 4, pp. 3410-3423, 2021, doi: 10.11591/ijece.v11i4.pp3410-3423.

[10] R. Piyare and M. Tazil, "Bluetooth based home automation system using cell phone," 2011 IEEE 15th International Symposium on Consumer Electronics (ISCE), 2011, pp. 192-195, doi: 10.1109/ISCE.2011.5973811.

[11] A. S. Kaittan, "Analysis and evaluation of power quality issues in computer-based generation system using custom power devices," in International Journal of Civil Engineering and Technology (IJCIET), vol. 10, no. 4, pp. 18701879, April 2019.

[12] H. G. Abood, G. A. Salman, and A. S. Kaittan, "A Regularized Approach for Solving Ill-Conditioned State Estimation of Distribution Systems," Elektrotehniski Vestnik, vol. 86, no. 3, pp. 137-143, 2019.

[13] A. S. Kaittan, "Comparison study between solid and litz wires of induction cooker," 2018 1st International Scientific Conference of Engineering Sciences - 3rd Scientific Conference of Engineering Science (ISCES), 2018, pp. 86-91, doi: 10.1109/ISCES.2018.8340533.

[14] M. H. Ali, "Mathematical Driving Model of Three Phase, Two Level Inverter by (Method of Interconnected Subsystem)," Iraqi Journal for Electrical and Electronic Engineering, vol. 13, no. 1, pp. 73-82, 2017. 
[15] M. H. Ali. "Design and Implementation of an Electrical Lift Controlled using PLC," International Journal of Electrical and Computer Engineering (IJECE), vol. 8, no. 4, pp. 1947-1953, 2018, doi: 10.11591/ijece.v8i4.pp1947-1953.

[16] S. M. Hameed, "Improvement The DFIG Active Power with Variable Speed Wind using Particle Swarm Optimization," Diyala Journal of Engineering Sciences, vol. 9, no. 2, pp. 12-22, June 2016, doi: 10.24237/djes.2016.09205.

[17] H. K. I. Al-Qaysi and S. M. Hameed, "Enhancing the Gain and Power of Folded-cascode Amplifier using Artificial Neural Network," International Journal of Engineering Research and Technology, vol. 12, no. 7, pp. 1117-1125, 2019.

[18] H. A. Hasan and S. M. Hameed, "Characteristics of Earth Electrodes Under High Frequency Conditions: Numerical Modelling," IOP Conference Series: Materials Science and Engineering, 2020, vol. 671, doi: 10.1088/1757-899X/671/1/012043.

[19] M. H. Ali, "Speed Control of (Sedm) Adopting Chopper Converter and Pi Controller," Diyala Journal of Engineering Sciences, vol. 8, no. 4, pp. 355-364, 2015.

[20] A. N. Abdullah and M. H. Ali, "Direct torque control of IM using PID controller," International Journal of Electrical \& Computer Engineering (IJECE), vol. 10, no. 1, pp. 617-625, 2020, doi: 10.11591/ijece.v10i1.pp617625.

[21] M. H. Ali and Q. A. Azze, "Design and implementation a security system for bank using voice recognition," International Journal of Power Electronics and Drive Systems (IJPEDS), vol. 10, no. 4, pp. 2126-2129, 2019, doi: 10.11591/ijpeds.v10.i4.pp2126-2129.

[22] Q. A. Azze and M. H. Ali, "Design and implement of pulse width modulation with low-cost hardware in the loop," International Journal of Power Electronics and Drive System (IJPEDS), vol. 11, no. 2, pp. 870-878, June 2020, doi: 10.11591/ijpeds.v11.i2.pp870-878.

[23] H.-T. Lin, "Implementing Smart Homes with Open-Source Solutions," International Journal of Smart Home, vol. 7, no. 4, pp 289-295, July 2013.

[24] A. F. Symon, N. Hassan, H. Rashid, I. U. Ahmed and S. M. Taslim Reza, "Design and development of a smart baby monitoring system based on Raspberry Pi and Pi camera," 2017 4th International Conference on Advances in Electrical Engineering (ICAEE), 2017, pp. 117-122, doi: 10.1109/ICAEE.2017.8255338.

[25] K. Mohanraj, N. Balaji, and R. Chithrakkannan, "IoT Based Patient Monitoring System Using Raspberry Pi 3 and LabVIEW," Pak. J. Biotechnol, vol. 14, no. 3, pp. 337-343, 2017.

\section{BIBLIOGRAPHY OF AUTHORS}

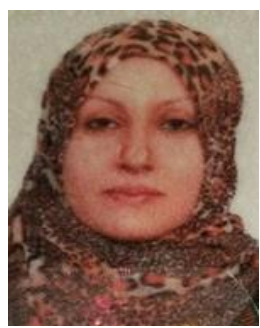

Nisreen Kareem Ali earned a bachelor's degree in science from the University of Diyala in Iraq in 2006 and a master's degree in science from the University of Belgorod in Russians in 2013. She is presently an assistant lecturer at Heteen Secondary School in Diyala, Baquba, Iraq, in the Electrical Engineering Department.

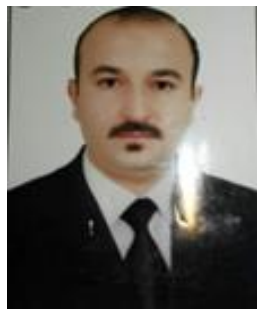

Mustafa Yaseen Abdulateef obtained his B. Sc from Diyala University, Iraq in 2008, he is interesting work in control, protection and power electronics

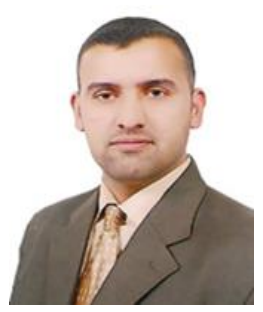

Mohammed Hasan Ali was born in the Iraqi city of Diyala in 1980. He obtained his B.Sc. from the University of Diyala in 2006 and his M. Sc. in 2013. He is presently a lecturer at the University of Diyala Department of Electrical Power Engineering. Professional Capabilities and Strengths: power quality, renewable energy, and power electronics are among his current research interests. He has ten years of experience as an electrical engineer. He teaches various fundamental Electrical Engineering disciplines at the University of Diyala in Iraq. He has 13 papers that have been published. 